\title{
Expressions of Gratitude: A Case of EFL Learners
}

\author{
Reza Pishghadam (Corresponding author) \\ English Department, Ferdowsi University of Mashhad \\ PO box 91779-48974, Park Square, Ferdowsi University Mashhad, Iran \\ E-mail: rpishghadam@yahoo.com \\ Sima Zarei \\ English Department, Ferdowsi University of Mashhad \\ PO box 91779-48974, Park Square, Ferdowsi University Mashhad, Iran \\ E-mail: sima.zarei@yahoo.com
}

$\begin{array}{lcc}\text { Received: July 25, 2011 } & \text { Accepted: August 20, } 2011 \quad \text { Published: December 1, } 2011 \\ \text { doi:10.5539/res.v3n2p140 } & \text { URL: http://dx.doi.org/10.5539/res.v3n2p140 }\end{array}$

\begin{abstract}
This study investigates the strategies Iranian English learners employ for expressing gratitude in different situations. To this end, 180 students from the English language institutes and universities in Mashhad were asked to take an open-ended Discourse Completion Task. The results showed that Iranian learners feel obliged to show gratitude to others in every form possible for the favor they receive, and they use mainly thanking and positive feeling strategies. The findings of Chi-square test also suggested that female Persian speakers use gratitude strategies more often than male ones. Finally, the results were discussed in the context of foreign language learning.
\end{abstract}

Keywords: Pragmatics, Speech act, Speech act of gratitude, EFL context

\section{Introduction}

Producing the appropriate language in different situations is essential to successful communication. In order to achieve this goal, one should acquire pragmatic competence alongside the grammatical one. Crystal (1997 as cited in Kasper and Rose, 2001) defined pragmatics as "the study of language from the point of view of the user, especially of the choices they make, the constraint they encounter in using language in social interaction and the effects of their use of language on other participants in the act of communication". Mey (1993) has also mentioned that pragmatics is the science of language which people use in their real life for achieving their purposes. One of the most fundamental parts of pragmatics is speech act that is defined by Austin (1962) as actions which are performed in saying something (as cited in Cutting, 2002). Being able to employ speech acts appropriately can be defined as having the knowledge to communicate with others (Eisenstein and Bodman, 1986). One of the most commonly used speech acts in everyday interaction is the gratitude speech act.

We express gratitude through words of thanks, praise or appreciation. Van Ek (1977, as cited in Eisenstein and Bodman, 1986) stated that the word "thank you" expresses emotional attitude and there are several phrases which may be used by speakers in thanking. Since thanking has a societal function, learners should acquire rules for expressing gratitude in the target language. From the fact that thanking is implemented by means of standardized routines, learners not only should know the semantic formulas needed in thanking situations but also have to understand the appropriate time to use these formulas (Blum-Kulka, 1984).

Moreover, a lot of factors influence the everyday language and use of speech act, among which gender is one. Men and women use language differently (Wardhaugh, 2002), so in order to prevent blaming others or ourselves these differences should be identified. Males and females have different strategies in delivering gratitude. Therefore, it is very important to know how males and females produce gratitude in conversation. Thus in this paper, we have considered two goals. Firstly, we have examined the types of gratitude strategies employed by EFL learners. And secondly, we aim at the types of gratitude strategies which are used by males and females in the context of EFL education. 


\section{Theoretical Background}

Thanking in Searle's typology (1976) is defined as the performance of an action by a speaker on a past act done by a hearer for whom it is beneficial. In Leech's classification (1983), the illocutionary goal of thanking is defined as appreciation, creating a friendly and polite atmosphere. Moreover, the speech act of thanking is behabitative in Austin (1962) speech acts categorization. Brown and Levinson (1987, as cited in Koutlaki, 2002) also classified thanking as a face threatening act in which the speaker feel obliged to acknowledge a debt to the hearer.

Based on the societal function of thanking which is introduced at early stages of life, Eisenstein and Bodman (1968) mentioned that if expressions of gratitude are used appropriately, they can provide feelings of warmth and solidarity among interlocutors. Expressions of gratitude can be grouped as simple, phatic utterance to lengthy communicative events developed by both giver and recipient of a gift, favor, reward, and service.

Comparing the American and British English, Hymes (1971) described that' Thank you' in American English is a formulaic expression of gratitude, whereas British English used it as a discourse marker or a conversational sequencer. He also mentioned that rules of politeness in expression of gratitude do not take indebtedness, relative status, gender, and age into consideration. In another study, Apte (1974) investigated the expressions of gratitude in American culture. He concluded that the Americans expressed their appreciation for all kinds of favors, gifts, and compliments in various situations. The expressions of gratitude included the word thank, as in many thanks, thank you, and thank you very much. Hinkel (1994) also explored the cultural differences in the attitudes toward the speech act of thanking. Results revealed that differences existed in perception of the appropriateness of certain expressions of thanks between nonnative English language groups and native English speakers.

To come up with cross cultural pragmatics problem differences, Intachakra (2004) conducted a study on comparison of speech act of thanks in English and Thai to discuss the pragmatic differences through natural observation. Analyzing data, he generalized that British English speakers tend to thank each other directly in comparison to Thai speakers due to increased number of strategies. Despite the fact that both cultures have the same communicative goals in expressing gratitude, their thanking strategies are different. He mentioned that Thais cannot express thanks as effectively as British, and they prefer to choose a practical method for expressing gratitude. In another study, Kashdan, Mishra, Breen and Froh (2009) conducted a study on gender differences in gratitude. He found out that men's expression of gratitude is less familiar and more discomforting compared with women's. Men's gratitude is more challenging and anxiety provoking and strengthens social bonds.

Cheng (2005) also studied the similarities and differences between native speakers of Chinese and native speakers of English in expression of gratitude by examining the length of their utterances and their use of strategies through a discourse completion task questionnaire. He also examined the sign of pragmatic development and the influence of their first language on producing the expressions of gratitude in the speech act behavior among Chinese learners of English. The results showed that Chinese and English native speakers had different choices of thanking strategies. The findings of his study revealed that the difference in length of speech and use of strategies were affected by contextual variables, social status, and familiarity. In another study, Johansen (2008) investigated gratitude expressions in Norwegian and English. He concluded that the length of Norwegian responses was similar to that of American ones. However, the responses given by Norwegians in English were generally longer than both the Norwegian responses and the native-English responses. Long (2010) also analyzed the use of apology strategies in Japanese gratitude situations by gathering data on the basis of an open ended questionnaire to see the difference in using expressions in different situations with various interlocutors. He noted that two factors affected using apology: 'regret and expectedness'. The researcher claimed that apology was used to recognize the relationship boundaries and further explained that children acquired these negotiations of role relations gradually though socialization process. In another study, Wong (2010) analyzed the expressions of gratitude containing the stem of "thanks" among Chinese speakers of English. The results revealed that Chinese expressions were brief and were used frequently as closing signal, and also they were too reserved to express gratitude explicitly. Fauziah (2010) also compared and contrasted gratitude expressions and responses between male and female characters of Rachel Getting Married movie based on Hymes's theory of gratitude expressions. The researcher found out that women were more polite in expressing gratitude in all conditions and situations, and their utterances were longer. Men, on the other hand expressed gratitude much in formal situation.

Regarding Persian, Farnia and Rozina (2009) studied the expressions of gratitude by Iranian EFL learners. They reported that Iranian and American respondents employed the same patterns of strategies in responding to the 
questionnaires. However, the findings of this study suggested that language proficiency did not affect EFL learners' use of strategies when expressing gratitude in the English language.

\section{Purpose of Study}

Since there are few studies (e.g. Farnia and Rozina, 2009) which have examined expressions of gratitude by Iranian EFL learners, the present study aims at investigating the expressions of gratitude which are produced by university students and learners in private language institutes. Therefore, this study addresses the following research questions:

Q1: Are there any significant differences between expressions of gratitude strategies used by Iranian EFL learners?

Q2: Are there any significant differences between male's and female's expressions of gratitude as Iranian EFL learners?

\section{Methodology}

\subsection{Participants and setting}

The total population participating in this study consisted of 180 individuals (female $=90$, male $=90$ ) who were all native speakers of Persian. They were students whose age ranged from 22 to 26, and were studying English as a foreign language in Mashhad (a city in Iran) in Ferdowsi University and private language institutes. The ones chosen from Mashhad University were all undergraduate and graduate students majoring in English language, and those from private institutes were all upper intermediate students studying English.

\subsection{Instrumentation}

In order to address the research questions, the participants were asked to complete a Discourse Completion Task (DCT) designed by Eisenstein and Bodman (1993), which took 20 minutes to answer the questions. The content validity of this questionnaire was substantiated through a pilot study done on 10 some students. Based on the recommendations and feedback received from the participants, questions were revised and taken into consideration for forming the final DCT (see Appendix 1). Finally, the scenarios in the DCT were modified and adapted to the Iranian context of English learning. The DCT was administered to the participants who responded to 14 situations which required them to feel, to different degree, obliged or grateful to someone who has done something for them or requested a favor. The participants were supposed to imagine themselves in each situation and respond accordingly based on their immediate reaction.

\subsection{Procedure}

The process of data collection started in November (2010) and continued until March (2011). In this study, for gathering the data, a DCT instrument was employed in which the participants pictured themselves in the situations and responded accordingly. They wrote down as many words or utterances as they wanted to express their gratitude towards the speaker.

For analyzing the data, the first step was to identify the gratitude strategies in the provided utterances. The respondents' answers were coded in accordance with a coding scheme proposed by Cheng (2005). It is based on 8 strategies for expression of gratitude:

1) Thanking

A. thanking comprising simple thanking by only using the word 'thank you'

B. thanking by stating the favor (thank you for your help, and thank you for your notice exemplify this sub-strategy)

C. thanking and mentioning the imposition caused by the favor (Thank you for helping me cleaning the room)

\section{2) Appreciation}

A. using the word appreciate (e.g. I appreciate it!)

B. using the word "appreciate" and mentioning the imposition caused by the favor (e.g. I appreciate the time you spent for me)

3) Repayment
A. offering services, food...(next time is my turn)
B. feeling indebted (I owe you one) 
C. promising future self-improvement (it won't happen again)

4) Recognition of imposition

A. by acknowledging the imposition (exemplified by statements such as I know you are not allowed to give me extra time)

B. stating or diminishing the need for the favor (you shouldn't do that)

5) Apology
A. using the apologizer words (I am sorry)
B. using apology by stating the favor (I am sorry for the problem I made)
C. expressing embarrassment (I feel embarrassed)
D. criticizing oneself ( I am such a fool...)

6) Positive feeling
A. expressing positive reaction to a person (You are a life saver)
B. expressing positive feeling to action (such as this book was really helpful)

7) Other

Expressions that do not belong to the mentioned strategies are categorized as other strategies comprising
A. here statements (here you are)
B. small talk
C. leave taking (good bye, have a nice day)
D. Joking

8) Alerter by using titles and names, attention getter in addition to the other strategies forms the alerter strategy.

The categorization was approved by two other experts in the field. Using SPSS (version 18.0), Chi-square was run to see whether there were any significant differences between the thanking strategies selected by the whole and also whether there were any significant differences between male and female expressions of gratitude sample or not.

\section{Results}

Analyzing the results of Chi-square $\left(\chi^{2}=3851.645, \mathrm{p}<.05\right)$, Table 1 exhibits that there is a significant difference in using thanking and positive feeling strategies. It describes that thanking strategy (observed $\mathrm{N}=1437$ ) is employed more often than expected $(\mathrm{N}=416.5)$ which means that participants used thanking strategies comprising simple thanking, thanking mentioning favor, thanking mentioning favor, and imposition extensively in their interactions. Also it revealed that participants used positive feeling strategy (observed N=752) more than expected ( $\mathrm{N}=416.5)$. It can be inferred from the results of the table that the Persian learners of English use thanking and positive feeling strategies as the two common strategies much more than the others.

As the results of Table 2 reveal, there is a significant difference between the use of thanking strategy, appreciation, positive feeling, repayment, and alerter among male and female participants.

The female participants used thanking strategy as the first most frequently used strategy $\left(\chi^{2}=28.677, \mathrm{p}<0.05\right)$. It implies that most female learners tend to thank others in every situation to observe rules of politeness. Their thanking was more elaborate. The second common strategy female participants used, was Positive feeling strategy $\left(\chi^{2}=11.255, \mathrm{p}<0.05\right)$. Repayment was the third most frequent strategy among females $\left(\chi^{2}=15.111, \mathrm{p}<\right.$ $0.05)$. The results showed that females feel much indebted towards their hearers, that is why they use more repayment strategies. Alerter was the fourth strategy used by females as Table 2 displayed $\left(\chi^{2}=204.753, p<\right.$ $0.05)$. The fifth frequent strategy was appreciation $\left(\chi^{2}=45.511, \mathrm{p}<0.05\right)$. Females were willing to express their gratitude to their hearers using appreciation strategies instead of simple or elaborate thanking when they are going to express their gratitude to someone in higher status.

It was indicated in Table 2 that male participants used alterer strategy more frequently $\left(\chi^{2}=204.753, p<0.05\right)$. Overall, the results of Chi-square indicated that there are not any significant differences between the usage of recognition of imposition, apology, and other strategies between male and female participants. 


\section{Discussion}

This study aimed at first investigating the types of strategies used in gratitude speech act among EFL learners, and second examining the role of gender in employing different strategies.

Considering the first objective of the study, the findings of the present study made it clear that Iranian learners of English mostly used thanking and positive feeling strategies and sub-strategies to express their gratitude since they thought they could show their indebtedness to the hearer by simple thanking or expressing their positive reaction either to action the hearer has done or the person who has done a favor. Scollon and Scollon (1995) claimed that although the same set of strategies appear in every language for performing a given illocutionary act, the preference for one strategy over the other is culture specific in communicative situations. Thanking would be the first preferred strategy in many cultures, what differs is its frequency that reflected cultural values. Similar to Cheng's findings (2005) people in American society believed that all are equal, and therefore should have same rights and opportunities. Like Iranian speakers, Americans use thanking frequently in their interactions as their preferred approach in expressing gratitude. Apte (1974) claimed that the reason that Americans use this strategy more is the value of egalitarianism, that speakers explicitly acknowledge things done for them with verbal thanks. They will choose their strategy whether they are thanking their friend, their boss, professor.

Bardovi-Harling and Rose and Nickels (2008) stated that the most commonly used strategies are acquired earlier, and since thanking is used as the essential strategy among participants, it may be concluded that EFL learners learn this strategy sooner and that's the reason why most cultures are similar in employing this strategy. Regarding the second most frequent strategy used by Iranian speakers-positive feeling- it may be due to the impact of their first language rules of speaking (Hosseinimanesh, 2011).

Considering the second goal, it is indicated that gender played a significant role in the process of expressing gratitude. Language learners employ strategies in various forms based on their individual characteristics (Hosseinimanesh, 2011). In this research, female learners felt the necessity to thank and appreciate everyone more than male ones did. It might be caused by a number of factors such as their social status, cultural norms, and degree of politeness. Moreover, it seems that female learners care more about saving face in their interactions by adding the alerter to their expressions. The findings in the present study are consistent with others in that females tend to express themselves in their daily interactions, whereas the reason males do not express emotions appears to be the vulnerability they may face which can affect their autonomy. Seen in this light, it is reasonable that females derived greater psychological benefits from thanking since it allows females to initiate, maintain, and strengthen relationships in expressing gratitude. Moreover, males seemingly view gratitude as challenging, anxiety provoking, and burdensome; and as a result preferred to avoid feelings of indebtedness in order to develop and strengthen relationships with others (Kashdan et al, 2009). Froh, Yurkewicz, and Kashdan (2009) stated that females experienced and expressed gratitude more than male did. The reason might be that females' utterances are more elaborate. Most females enjoyed talking and using language to establish personal relationships, while males viewed language as a tool for sending and receiving information. Females complimented, apologized, gratified more often than men did, and also they appreciated complimenting more (Coates, 1998). That is why they tend to use more positive reactions towards either their hearers or actions done. It appears that female learners employ repayment strategies due to their nature which tends to be more appreciative. This study certainly provides the evidence that male and female learners used language differently. Although the comparison in the use of the strategies between them revealed that they employed a similar pattern of strategy use and their responses were different in the frequency of utterances. Overall, the results of the present study are in line with the previous ones considering speech acts and speech behaviors which demonstrated that non-native speakers' production was different and seemed to be inadequate due to cultural differences (Bardovi-Harlig, 1999; Kasper and Schmidt, 1996).

Intachakra (2004) suggested that syllabus designers and teachers should empower learners with consciousness raising activities in order to enable them to produce native like expressions. Language instructors should provide students with life like situations and inform their learners about the differences gender can make in their use of language and especially speech acts like gratitude, in other words the proper content is essential to be taught in classroom. Introducing pragmatic competence can benefit the learners to a great deal. Ghobadi and Fahim (2009), gathering data from the explicit instruction group, concluded the positive effect of instruction on raising students' socio-pragmatic awareness. Cheng (2005) also suggested that introducing semantic formulas of an expression in target language should $\mathrm{b}$ alongside the proper context in order to help learners develop their pragmatic competence. 
More studies are needed to investigate in a larger number of institutes and universities. Furthermore, this study does not take language proficiency, social status, familiarity of the interlocutors with each other and personality factor into account, so it would be informative to find out whether these factors play important roles in the speech act of expressions of gratitude.

\section{References}

Apte, M. L. (1974). "Thank you" and South Asia languages: A comparative sociolinguistic study. Lingusitics, 136, 67-89. http://dx.doi.org/10.1515/ling.1974.12.136.67

Austin, J. L. (1962). How to do things with words. Oxford: Oxford University press.

Bardovi-Harlig, K. (1999). Exploring the interlanguage of Interlanguage pragmatics: A Research agenda for acquisitional pragmatics. Language Learning, 49(4), 677- 713. http://dx.doi.org/10.1111/0023-8333.00105

Bardovi-Harling, K., Rose, M., and Nickels, E. L. (2008). The use of conventional expressions of thanking, apologizing, and refusing. In proceeding of the 2007 second language research forum, Cascadilla Proceedings Project, Somerville, MA, pp. 113- 130. http://dx.doi.org/10.1111/0023-8333.00105

Blum-Kulka, S. and Olshtain, E. (1984). Requests and Apologies: A Cross-Cultural Study of Speech Act Realization Patterns. Applied Linguistics, 5(3), 196- 213. http://dx.doi.org/10.1093/applin/5.3.196

Brown, P. and Levinson, S. (1987). Politeness: Some universals in language usage. Cambridge: Cambridge University Press.

Cheng, S. W. (2005). An exploratory cross-sectional study of interlanguage pragmatic development of expressions of gratitude by Chinese learners of English. A doctoral dissertation, University of Iowa.

Coates, J. (1998). Women, men, and language: A sociolinguistic account of gender differences in language. Blackwell publishing.

Crystal, D. (1997). A dictionary of linguistics and phonetics. Cambridge: Blackwell.

Cutting, J. (2002). Pragmatics and discourse, Rutledge, London.

Eisenstein, M. and Bodman, J. W. (1986). "I very appreciate": Expressions of gratitude by native and nonnative speakers of American English. Applied Linguistics, 7, 167-185. http://dx.doi.org/10.1093/applin/7.2.167

Eisenstein, M. and Bodman, J. W. (1993). Expressing gratitude in American English. In G.Kasper and S. Blum-Kulka (Eds.), Interlanguage pragmatics (pp.64-81). New York: Oxford University Press.

Farnia, M. and Suleiman, R. (2009). An interlanguage pragmatic study of expressions of gratitude by Iranian EFL learners - A pilot study. Malaysian Journal Of ELT Research, 5,108-140.

Fauziyah, N. U. (2010). Gratitude expressions and gratitude responses of male and female characters in Rachel getting married movie. A docteral dissertation, Maulana Malik Ibrahim State Islamic University of Malang.

Froh, J. J., Yurkewicz, C. and Kashdan, T. B. (2009). Gratitude and subjective well-being in early adolescence: Examining gender differences. Journal of Adolescence, 32, 633-650. http://dx.doi.org/10.1016/j.adolescence.2008.06.006

Ghobadi, A. and Fahim, M. (2009). The effect of explicit teaching of English 'thanking formulas' on Iranian EFL intermediate level students at English language institutes. Science Direct, 37, 526-537. http://dx.doi.org/10.1016/j.system.2009.02.010

Hinkel, E. (1994). Pragmatics of interaction: Expressing thanks in second language. Applied Language Learning, 5, 53-91.

Hosseinimanesh, L. (2011). Cultural Differences between English and Persian in technical Translation. International Journal of English Linguistics, 1(1), 227-235.

Hymes, D. (1971). Sociolinguistics and the ethnography of speaking. In Ardener, E. (Ed.) social anthropology and language. Tavistock: London.

Intachakra, S. (2004). Contrastive pragmatics and language teaching: Apologies and thanks in English and Thai. RELC, 35(1), 37-62. http://dx.doi.org/10.1177/003368820403500105

Johansen, S.H. (2008). A comparative study of gratitude expressions in Norwegian and English from an interlanguage pragmatic and second language acquisition research perspective. A doctoral dissertation, University of Oslo. 
Kashdan, T. B., Mishra, A., Breen, W. E. and Froh, J. J. (2009). Gender differences in gratitude: Examining appraisals, narratives, the willingness to express emotions, and changes in psychological needs. Journal of Personality, 77, 691-730. http://dx.doi.org/10.1111/j.1467-6494.2009.00562.x

Kasper, G. and Rose, K. R. (2001). Pragmatics in language teaching. Cambridge: Cambridge University Press.

Kasper, G. and Schmidt, R. (1996). Developmental issues in interlanguage pragmatics. Studies in Second Language Acquisition, 18(2), 149-169. http://dx.doi.org/10.1017/S0272263100014868

Koutlaki, S. A. (2002). Offers and expressions of thanks as face enhancing acts: tæ' arof in persian. Journal of Pragmatics, 34(12), 1733-1756. http://dx.doi.org/10.1016/S0378-2166(01)00055-8

Leech, G. (1983). Principles of pragmatics. New York: Longman.

Long, C. (2010). Apology in Japanese gratitude situations: the negotiation of interlocutor role relations. Journal of Pragmatics, 42, 1060-1075. http://dx.doi.org/10.1016/j.pragma.2009.09.005

Mey, J. (1993). Pragmatics. Oxford: Blackwell.

Mustapha, A. S. (2003). Gender variation in Nigerian English compliments. A docteral dissertation, University of Essex.

Ruhi, S. (2000). Complimenting women in Turkish: Defining ingroupness and shaping identities. Nemeth, E. T. (ed.), Pragmatics in 2000. Antwerp: IPrA, 481- 495.

Scollon, R. and Scollon, S. (1995). Intercultural communication: A discourse analysis. Oxford: Blackwell.

Searle, J. R. (1976). A classification of illocutionary acts. Language in Society, 5, 1-24. http://dx.doi.org/10.1017/S0047404500006837

Van Ek, J. A. (1977). The threshold level of modern language learning in schools. London: Longman.

Wardhaugh, R. (2002). An introduction to sociolinguistics (4 ${ }^{\text {th }}$ ed.). Oxford: Blackwell Publishers Ltd.

Wong, M. L. (2010). Expressions of gratitude by Hong Kong speakers of English: Research from the International Corpus of English in Hong Kong, Journal of Pragmatics, 42, 1243-1257. http://dx.doi.org/10.1016/j.pragma.2009.09.022

\section{Appendix}

Dear participant,

Thank you for participating in this survey. This study is intended to explore cross cultural and Interlanguage speech behavior. The information you provide below will be used for this study only and will remain confidential. In the following section, please mark an ' $X$ ' between the boxes corresponding to your response.

\section{Background information:}

Name:

Intended/completed Degree: $\mathrm{BAO}$

\section{university:}

Year: FreshmanO SophomoreO JuniorO SeniorO

Age:

Gender: MaleO

FemaleO

\section{Instruction}

The purpose of this study is to better understand speakers, as English learners, would respond to the given situations and how their responses are near to those of English native speakers. Some situations and their corresponding questions may sound odd or unfamiliar to you. Please be honest when completing the survey because your responses are valuable to this study.

You will find the following scenarios involve being placed in a situation where you may feel, to different degrees, obliged or grateful to someone who has done something for or requested of/from you. Please imagine yourself in each situation and respond accordingly based on your immediate reaction. If you feel that a specified situation does not warrant a response, please provide an explanation. 


\section{The questionnaire:}

1. It is Friday. You look in your wallet and notice that you only have $\$ 2.00$. your good friend at work notices this and hears you say,' I'll have to go to the bank.' Your friend asks if you need money, and you say that you forgot to go to the bank. Your friend says, 'I have plenty. How much do you need?' You say, 'Could you lend me \$5.00? I'll pay you back on Monday.' Your friend says, 'Sure. Are you sure you don't need more than that?'Y ou say you don't. Your friend gives you the \$5.00.

\section{You would say nothing because:}

2. You board the bus, pay your money and take a seat near the front of the bus. Just before your stop, you guess that the driver is not going to stop. You move to the front, and ask the driver to stop and he stops.

You would say nothing because:

3. You board the bus, pay your money and take a seat near the front of the bus. Just before your stop, you guess that the driver is not going to stop. You move to the front, and ask the driver to stop and he stops.

\section{You would say:}

You would say nothing because:

4. You work for a large company, which is usually very busy. You send your manager a request for some days off. The vice-president of personnel calls you into his office. He tells you to sit down. You feel a little nervous, because you have only been working there for six months. The vice-president says, 'You're doing a good job. In fact, we are so pleased with you that I am going to give you a raise'.

You would say:

You would say nothing because:

5. In the supermarket, you ask the cashier to bag your groceries. He does this,and then turns to begin serving the next costumer. You pay and pick up your bags to leave.

You would say:

You would say nothing because:

6. At the table in a restaurant a friend says, you have something on your face.' You ask where. Your friend tells you. You rub your face and ask,'Is it off?' your friend says that it is.

You would say:

\section{You would say nothing because:}

7. You find yourself in sudden need of money--\$500. You mention this to a friend. Your friend immediately offers to lend it you. At first you say, 'Oh no, I didn't mean it as a request. I couldn't take it.' Your friend says,'Really, it's all right. What are friends for?' Your friend insists again, and you take the check.

You would say:

You would say nothing because:

8. You are studying in another city. Both you and your roommate work. You come home late from work and find that your roommate has done some work around the house that you had promised to do, but had not had a chance to do.

\section{You would say:}

You would say nothing because:

9. Your friend suggests going out to lunch. You say that you'd like to go, but you only have \$2. Your friend says. 'Ah, don't worry. I'll treat you today.' Your friend takes you to a very nice restaurant $-\mathrm{a}$ much more expensive one than you usually go to. You have a wonderful meal. Your friend pays, and you get up to leave.

You would say:

\section{You would say nothing because:}

10. You have just gotten an admission from a foreign university. A close friend in the university tells you she has organized a farewell party for you. 


\section{You would say:}

\section{You would say nothing because:}

11. You have just gotten your hair cut in a new style, and you like it better than the old one. Your friend sees it and you ask him what he thinks. He says, 'Hey, you've got a new haircut. It looks nice.'

\section{You would say:}

\section{You would say nothing because:}

12. You share an apartment with a friend. You're both sitting and relaxing in the living room. You ask your friend to hand you the newspaper which is nearby. Your friend gives you the newspaper.

\section{You would say: Thanks.}

\section{You would say nothing because:}

13. You enter a parking garage. As the parking attendant gives you the parking voucher, You hand him the money and ask him about the empty space.

\section{You would say:}

\section{You would say nothing because:}

14. You have been invited to the home of a rather new friend. You have dinner with him and his family and a few other friends of theirs. The food was great, and you really enjoyed the evening. As you leave, your hosts accompany you to the door.

\section{You would say:}

\section{You would say nothing because:}

Table 1. The results of the chi-square for the expressions of gratitude selected by the whole participants

\begin{tabular}{|c|c|c|c|c|c|}
\hline Strategies & Observed N & Expected N & Df & $\chi^{2}$ & Sign. \\
\hline Thanking & 1437 & 416.5 & 7 & 3851.645 & .000 \\
\hline Appreciation & 90 & 416.5 & & & \\
\hline Positive feeling & 752 & 416.5 & & & \\
\hline Repayment & 413 & 416.5 & & & \\
\hline Apology & 110 & 416.5 & & & \\
\hline Imposition & 36 & 416.5 & & & \\
\hline Alerter & 401 & 416.5 & & & \\
\hline Other & 93 & 416.5 & & & \\
\hline
\end{tabular}


Table 2. The results of the chi-square for the difference between gender and gratitude expressions

\begin{tabular}{|c|c|c|c|c|c|c|}
\hline Strategies & Gender & Observed N & Expected $\mathrm{N}$ & $\overline{\mathrm{Df}}$ & $\chi^{2}$ & Sig. \\
\hline \multirow[t]{2}{*}{ Thanking } & Female & 820 & 718.5 & \multirow[t]{2}{*}{1} & \multirow[t]{2}{*}{28.677} & \multirow[t]{2}{*}{.000} \\
\hline & Male & 617 & 718.5 & & & \\
\hline \multirow[t]{2}{*}{ Appreciation } & Female & 77 & 45 & \multirow[t]{2}{*}{1} & \multirow[t]{2}{*}{45.511} & \multirow[t]{2}{*}{.000} \\
\hline & Male & 13 & 45 & & & \\
\hline \multirow{2}{*}{$\begin{array}{l}\text { Recognition of } \\
\text { imposition }\end{array}$} & Female & 19 & 18 & \multirow[t]{2}{*}{1} & \multirow[t]{2}{*}{.111} & \multirow[t]{2}{*}{.739} \\
\hline & Male & 17 & 18 & & & \\
\hline \multirow[t]{2}{*}{ Positive feeling } & Female & 422 & 376 & \multirow[t]{2}{*}{1} & \multirow[t]{2}{*}{11.255} & \multirow[t]{2}{*}{.000} \\
\hline & Male & 330 & 376 & & & \\
\hline \multirow[t]{2}{*}{ Repayment } & Female & 246 & 206.5 & \multirow[t]{2}{*}{1} & \multirow[t]{2}{*}{15.111} & \multirow[t]{2}{*}{.000} \\
\hline & Male & 167 & 206.5 & & & \\
\hline \multirow[t]{2}{*}{ Apology } & Female & 65 & 55 & \multirow[t]{2}{*}{1} & \multirow[t]{2}{*}{3.636} & \multirow[t]{2}{*}{.057} \\
\hline & Male & 45 & 55 & & & \\
\hline \multirow[t]{2}{*}{ Other } & Female & 48 & 46.5 & \multirow[t]{2}{*}{1} & \multirow[t]{2}{*}{.097} & \multirow[t]{2}{*}{.756} \\
\hline & Male & 45 & 46.5 & & & \\
\hline \multirow[t]{2}{*}{ Alerter } & Female & 222 & 133.7 & \multirow[t]{2}{*}{2} & \multirow[t]{2}{*}{204.753} & \multirow[t]{2}{*}{.000} \\
\hline & Male & 178 & 133.7 & & & \\
\hline
\end{tabular}

